\title{
AS TIC NA EDUCAÇÃO DE JOVENS E ADULTOS: RESSIGNIFICANDO E RECONSTRUINDO ESPAÇOS DE SABERES
}

\author{
ICT IN YOUTH AND ADULT EDUCATION: RE-MEANING AND RE-BUILDING KNOWLEDGE \\ SPACES
}

\section{LAS TIC EN LA EDUCACIÓN JUVENIL Y ADULTA: REEMPLAZANDO Y RECONSTRUYENDO ESPACIOS DE CONOCIMIENTO}

\author{
Givanildo da Silva \\ Ailton Rodrigues dos Santos \\ Pollyana Cássica Gonzaga Ferreira
}

\begin{abstract}
RESUMO
O uso das tecnologias no ambiente escolar é indispensável para que auxiliem no processo pedagógico aos docentes e aos discentes, visando garantir a oferta do ensino público noturno de qualidade nas suas diferentes etapas e modalidades. $O$ estudo apresentado tem como objetivo compreender a importância do uso das TIC no ensino da Educação de Jovens e Adultos (EJA). Nessa perspectiva, a pesquisa teve como questão norteadora a seguinte indagação: qual é a contribuição das TIC na Educação de Jovens e Adultos? A metodologia da pesquisa esteve pautada na abordagem qualitativa, tendo como suporte a pesquisa bibliográfica. Os principais resultados apontaram que a EJA necessita de aulas que identifiquem e proponham a inclusão, o acesso e o domínio das tecnologias aproximando os estudantes de suas reais necessidades, garantindo a mediação no contexto do ensino e da aprendizagem, bem como a permanência e a sequência nos estudos.
\end{abstract}

PALAVRAS-CHAVE: TIC. EJA. Mediação Pedagógica.

\section{ABSTRACT}

The use of technologies in the school environment is indispensable to help teachers and students in the pedagogical process, aiming to ensure the provision of quality night public education in its different stages and modalities. The present study aims to understand the importance of the use of ICT in the teaching of Youth and Adult Education (EJA). From this perspective, the research had as its guiding question the following question: What is the contribution of ICT in Youth and Adult Education? The research methodology was based on the qualitative approach, supported by bibliographic research. The main results indicated that the EJA needs classes that identify and propose the inclusion, access and mastery of technologies bringing students closer to their real needs, ensuring mediation in the context of teaching and learning, as well as permanence and sequence. in the studies.

KEYWORDS: ICT. EJA. Pedagogical Mediation.

\section{RESUMEN}

El uso de tecnologías en el entorno escolar es esencial para ayudar a los docentes y estudiantes en el proceso pedagógico, con el objetivo de garantizar la provisión de una enseñanza nocturna pública de calidad en sus diferentes etapas y modalidades. El estudio presentado tiene como objetivo comprender la importancia del uso de las TIC en la educación de la educación de jóvenes y adultos (EJA). En esta perspectiva, la investigación tuvo como pregunta orientadora la siguiente pregunta: ¿cuál es la contribución de las TIC en la educación de jóvenes y adultos? La metodología de investigación se basó en el enfoque cualitativo, basado en la investigación bibliográfica. Los principales resultados señalaron que EJA necesita clases que identifiquen y propongan la inclusión, el acceso y el dominio de las tecnologías, acercando a los estudiantes a sus necesidades reales, asegurando la mediación en el contexto de la enseñanza y el aprendizaje, así como la permanencia y la secuencia. en estudios

PALABRAS CLAVE: TIC. EJA Mediación pedagógica.

Revista de Ciências Humanas, Frederico Westphalen - RS, v. 21, n.2, p. 11-24, maio/ago. 2020. 


\section{Introdução}

A apropriação e o uso das Tecnologias de Informação e Comunicação (TIC) no atual contexto da educação brasileira redimensionam para novas práticas e aptidões diante das perspectivas e desafios do ensino e da aprendizagem. Neste sentido, o uso das tecnologias no ambiente escolar é indispensável para que auxiliem no processo pedagógico aos docentes e aos discentes, visando garantir a oferta do ensino público noturno de qualidade nas suas diferentes etapas e modalidades. Os diferentes recursos tecnológicos ampliam e maximizam as possibilidades de atuação do professor e das suas atividades pedagógicas para que possa atingir os seus objetivos.

Dessa forma, as reflexões e as discussões sobre o uso das TIC na Educação de Jovens e Adultos (EJA) serão direcionadas para a importância do papel das tecnologias na educação desse público. Diante da atual necessidade da oferta de ensino de qualidade associada à responsabilidade social e cultural da escola em suas diferentes etapas e modalidades de educação, a pesquisa pode contribuir como elemento reflexivo para que educadores, educandos, diretores, coordenadores, entidades públicas e privadas, como também aqueles interessados em temáticas educacionais, possam analisar e refletir sobre o uso das tecnologias na Educação de Jovens e Adultos.

A vivência das TIC no contexto do ensino público e privado e, em especial, no auxílio das práticas pedagógicas, não pode configurar-se, simplesmente, no campo das reflexões teóricas ou na modicidade da sociedade digital. É fundamental que as tecnologias sejam apropriadas e utilizadas para diversos sentidos e significados correlacionados ao processo de ensino e de aprendizagem e que possam servir como instrumento de interação, transformação e inserção dos seus usuários às novas necessidades da sociedade. A autonomia da escola baseada na democracia permite que as instituições de educação pública direcionem o seu projeto políticopedagógico (PPP) para que oportunizem o uso das tecnologias na aprendizagem, como elementos que conduzam para novas oportunidades de conhecimentos e engajamentos sociais.

Uma parte significativa das escolas públicas do século XXI trilha diante de perspectivas e possiblidades no que se refere ao uso das tecnologias e ao desafio da oferta de um ensino de qualidade (MARTINS, 2002). A educação pública, subjetiva e gratuita, como preconiza a Constituição Federal de 1988, está associada à responsabilidade da União, dos estados e dos municípios em oferecer educação para todo aquele que necessita e acredita na possibilidade de 
adquirir conhecimentos como objetivo de transformação e emancipação humana. Mudar, para isso, significa também refletir sobre significado do ensino e a sua oferta, na qual se pretende ir e para onde se quer chegar. Neste sentido, um ensino acessível, democrático e de qualidade permite analisar e refletir sobre novas práticas pedagógicas que vislumbram o uso das tecnologias como elemento que pode mediar diferentes formas de aprendizagens em diferentes contextos da educação (CARVALHO, 2006).

Entendemos que, para a concretização do ensino de qualidade, a escola deve utilizar diversos mecanismos e instrumentos pedagógicos e colaborativos que deem suporte durante todo o percurso para a construção do conhecimento. Nessa perspectiva, o currículo e o planejamento são dimensões importantes da base teórica que referenciam as atividades escolares. Entretanto, o fazer pedagógico marcado pela intencionalidade e na motivação da atuação docente associados à teoria são elementos indissociáveis para a efetivação da qualidade e oferta de ensino (CAPUCHO, 2002)

Dessa forma, a inserção das tecnologias no ambiente escolar proporciona novas descobertas e interações da socialização do conhecimento, ampliando, assim, o repertório de possibilidades que atualizam a atuação do professor em sala de aula, tornando o aprendizado significativo e democrático (MARTINS, 2002). Nessa ótica, o estudo apresentado tem como objetivo compreender a importância do uso das TIC no ensino da Educação de Jovens e Adultos.

Nessa perspectiva, a pesquisa apresentada tem como problemática: Qual é a contribuição das TIC na Educação de Jovens e Adultos? Assim, compreendemos que o uso das Tecnologias da Comunicação e Informação pode e deve garantir a melhoria da qualidade do ensino e da aprendizagem, favorecendo maior interação entre os envolvidos e promovendo a inclusão no contexto digital.

A proposta de desenvolvimento da pesquisa nasceu das experiências em sala de aula, como professor de Geografia da rede pública e privada, das diferentes séries do ensino fundamental e médio, e, em especial, na modalidade da EJA. Durante minha atuação como professor e em contato com os alunos do período noturno, pude perceber que existe uma falta de interesse por parte dos discentes ao que se trabalhar na sala de aula, isso porque esse público traz para o contexto escolar experiências de altas jornadas de trabalho, que somadas a inúmeros fatores sociais, contribuem para a evasão escolar.

A escolha por direcionar a pesquisa para essa modalidade está relacionada ao uso das tecnologias de aprendizagens de modo que venham a ressignificar as práticas educacionais da EJA no contexto da educação pública noturna. De acordo com a Lei de Diretrizes e Bases da 
Educação, 9.394, de 20 de dezembro de 1996, a modalidade de ensino EJA é oferecida para todos aqueles (jovens, adultos e idosos) que não tiveram acesso à educação convencional em idade apropriada.

A metodologia da pesquisa esteve pautada na abordagem qualitativa, tendo como suporte a pesquisa bibliográfica. A revisão da Literatura foi compreendida como "o referencial teórico de um pesquisador pelo qual ele enxerga a realidade, sugerindo perguntas e indicando possibilidades" (LUNA, 2000, p. 32). Essa foi uma importante parte da pesquisa a ser desenvolvida, uma vez que o levantamento de discussões sobre a temática em questão seria a melhor estratégia para as problematizações.

O artigo está estruturado em três partes que se completam, além da introdução e das considerações finais. Na primeira parte, foi feito um breve relato sobre as transformações ocasionadas pelas TIC, nos mais variados campos da sociedade contemporânea, sendo a globalização um elemento potencializador desse fenômeno. No segundo momento, discutimos, através de um relato historiográfico, o modelo de educação implantado nas terras brasileiras e a oferta da EJA e a sua trajetória para o reconhecimento e a regulamentação oficial pelas instituições democráticas do país. Dando sequência, o terceiro momento é caracterizado pelo fortalecimento da EJA mediada pelas tecnologias, visando às novas possibilidades de autonomia e qualidade na oferta do ensino público.

\section{O mundo contemporâneo e as tecnologias da informação e comunicação}

A sociedade global passou e vem passando por transformações em diferentes campos das ciências econômicas, política, filosófica e social. Essas mudanças estão relacionadas ao desenvolvimento das técnicas e das tecnologias e têm como elemento norteador a globalização. Neste sentido, "entre os múltiplos aspectos do período atual é fundamental conhecer a nova revolução científica" (SANTOS, 1988, p. 13).

A ciência associada à tecnologia promoveu de forma significativa uma revolução das relações sociais, isso porque "a ciência particularmente no campo das comunicações e da eletrônica, introduziu inovações que alteraram profundamente alguns aspectos do modelo de sociedade que havíamos conhecidos até alguns anos atrás" (MAGALHÃES, 2004, p. 36).

Os novos conhecimentos produzidos direcionam a sociedade a reconstruir ou ressignificar hábitos e posturas individuais e coletivas. O mundo digital afeta a vida de grande parte dos seres humanos nas mais variadas formas possíveis de consumo, locomoção, 
experiências e diálogos. Essas necessidades geradas pelas tecnologias da informação e da comunicação despertam em parte da população o desejo de adquirir novos conhecimentos que conduzem a ampliar ou dialogar com os já existentes.

Entretanto, "o avanço do mundo digital traz inúmeras possibilidades, ao mesmo tempo em que deixa perplexas as instituições sobre o que aprender, o que manter, o que adotar" (MORAM; MASSETO; BEHRENS, 2013, p. 11). Refletir sobre a apropriação das TIC no atual contexto da educação brasileira é desafiador, pois indica a necessidade de adotar uma nova postura para dialogar com pensamentos e estruturas conservadoras que surgiram no passado, mas que se mantêm no presente. A mudança requer dialogar com paradigmas, "romper" conceitos e preconceitos, objetivando visualizar e caminhar em outras direções.

Em uma perspectiva de mudanças, a sala de aula não deve e não pode mais ser vista como o lugar exclusivo da disseminação do conhecimento produzido pelas ciências e pelas relações sociais, mas que garanta efetivamente a independência e a autonomia com qualidade do ensino (CUNHA, 2006). O status de exclusividade do professor, como centro do conhecimento, que ministrava aulas tradicionais baseadas na memorização e reprodução de conteúdos, aos poucos vem dando lugar para aulas interativas, reflexivas e democráticas, em que as TIC têm apresentado importantes caminhos para esse modelo, exigindo por parte do aluno, de forma individual ou coletiva, autonomia na construção do seu conhecimento.

Nessa perspectiva, "com as tecnologias atuais, a escola pode transformar-se em um conjunto de espaços ricos de aprendizagens significativas, presenciais e digitais, que motivem os alunos a aprender ativamente, a pesquisar a todo tempo, a serem proativos, a tomar iniciativas e interagir" (MORAM; MASSETO; BEHRENS, 2013, p. 31). Dessa forma, refletir sobre as possibilidades do uso das TIC na escola faz-se necessário com a finalidade de inserir as práticas educativas no contexto das ações contemporâneas, permitindo novas configurações e dinâmicas educacionais.

O progresso das ciências associado ao desenvolvimento de diversos programas digitais e aparelhos tecnológicos permitiram uma maior interação e conectividade entre alunos e professores, contribuindo, assim, para o processo de ensino e de aprendizagem. Essa interação e desejo de aprender conduz a novos caminhos da flexibilização do conhecimento. A Base Nacional Comum Curricular (BNCC) reforça o compromisso de estabelecer novas relações de aprendizagens por meio das tecnologias, em que o sistema de ensino precisa estar envolvido, possibilitando novas interações por meio das TIC. No mundo contemporâneo, é importante a 
utilização de diferentes formas e plataformas de comunicação, tendo em vista que as múltiplas ações sociais estão priorizando as tecnologias como forma de organização das práticas sociais.

Dessa forma, a escola deve ser vista como um espaço de aprendizagem. É nela que depositamos toda a nossa confiança na realização dos nossos sonhos, movidos pelo ideal de crescimento de desenvolvimento pessoal e coletivo. É também nesse espaço que dialogamos sobre valores universais que são indispensáveis para toda a vida como: respeito, dignidade, honestidade e solidariedade. Todavia e em especial, a sala de aula deve e pode ser local da amplitude de significados construídos e baseados em uma educação libertadora e progressista viabilizando o convívio em sociedade (BATTESTIN; WEYH, 2019).

\section{A Educação de Jovens e Adultos: apontamentos iniciais}

Historicamente, a educação oferecida nas terras brasileiras, desde o período colonial e durante muito tempo, foi marcada pelos ideais do modelo de economia capitalista, atribuído a um país subdesenvolvido que estava inserido no mundo do trabalho. A ocultação do não oferecimento de direitos e garantias sociais como saúde, educação, lazer, entre outros aspectos essenciais à vida humana, gerou, com o passar dos anos, um grande número de homens, mulheres, idosos e crianças que, mediante fatores econômicos, políticos e sociais, não tiveram acesso à educação em idade própria.

No Brasil do século XX, o período conhecido como governos militares (1964-1985) foi marcado por regimes autoritários que legitimaram o seu poder através da força e da submissão da população (CAPUCHO, 2012). O totalitarismo e o fascismo manipulavam interesses das minorias tendo em vista exercer o controle das massas menos favorecidas, relegando a educação pública ao segundo plano. A negação da oferta de ensino formal e de qualidade à classe trabalhadora foi um projeto adotado para que possíveis rebeliões ou levantes populares não colocassem em cheque o sistema vigente das elites no Brasil. Sendo assim, era necessário manter uma significativa parte da população no obscurantismo e na ignorância, pois, desse modo, 0 projeto perpetuava-se sem nenhum questionamento, triunfando como modelo ideal de um Brasil governado pela burguesia elitista (CAPUCHO, 2012).

Ao longo de anos, a manutenção da ordem foi realizada utilizando a negação de direitos e garantias individuais e coletivas indispensáveis para o exercício da cidadania. Nesse contexto, as ideias do capitalismo liberal difundidas no Brasil no início da década de 1990 encontraram terreno ideal para ampliar o projeto da globalização visando corroborar com a fragmentação de políticas educacionais que atuassem de forma efetiva no país. Desse modo:

Revista de Ciências Humanas, Frederico Westphalen - RS, v. 21, n.2, p. 11-24, maio/ago. 2020. 
O Estado brasileiro capitalista se consolidou como periferia, negando direitos sociais básicos como saúde, educação e seguridade social. A trajetória do direito a educação expressos nas constituições brasileiras - desde a Constituição Imperial de 1824 até a Constituição de 1988 - mostra que, ao longo de mais de um século e meio, o direito à educação vinha sendo oficialmente negado aos (às) jovens e adultos (as) que não tiveram acesso á escola na idade tida como apropriada (CAPUCHO, 2012, p.24).

As discussões e regulamentações da EJA no Brasil remetem à Constituição Federal de 1988, quando esta tornou-se um marco referencial que previa/determinava a responsabilidade do Estado como ente federativo que deveria oferecer o ensino fundamental obrigatório e gratuito nas diversas etapas e modalidades. Esse dever ficou preconizado quando as instituições de ensino passaram a ter o compromisso de assegurar a permanência de jovens e adultos na escola, garantindo oportunidades apropriadas e ensino baseado nas características da vida e do trabalho.

A oferta de educação de qualidade para jovens e adultos na rede pública no período noturno remete à análise das características e especificidades desse público-alvo. AEJA, segundo o artigo 37 da LDB/1996, é oferecida a todo aquele que não teve acesso à escola na idade convencional. É fundamental perceber o perfil do público que frequenta o ensino na modalidade EJA, suas diferentes características de faixa etária, gênero e conhecimento histórico cultural para o desenvolvimento de suas atividades. Assim:

O termo educação de jovens e adultos não nos remete somente a uma questão de
especificidade, mas, primordialmente a uma questão de especificidade cultural, isto é,
apesar do corte por idade (Jovens e Adultos são basicamente, não crianças). Esse
território da educação não diz respeito a reflexões e ações dirigidas a qualquer jovem
ou adulto, mas delimita um determinado grupo de pessoas relativamente homogêneo
no interior da diversidade de grupos culturais da sociedade contemporânea.
(OLIVEIRA, 2005, p. 15).

Conhecer as características da realidade da EJA é entender e perceber que o ensino desenvolvido para os educandos dessa modalidade não pode basear-se especificamente na alfabetização, memorização e repetição, isso porque "para ser um ato de alfabetizando dos adultos é fundamental que exista uma relação de intenso diálogo entre educadores e educandos" (FREIRE, 2007, p. 58).

É necessário criar diferentes estratégias curriculares e pedagógicas que busquem inserir as novas demandas do mundo interconectado pelas tecnologias junto aos estudantes, possibilitando uma educação que os conduza para o processo de criatividade, interação e conhecimento de novas dimensões sociais. Nesse mundo de constantes transformações, 0 docente também é conduzido a capacitar-se motivadamente para uma educação continuada que atue efetivamente na busca pela qualidade, adaptando o seu plano de ensino, a sua metodologia e a sua prática de ensino às exigências sociais.

Revista de Ciências Humanas, Frederico Westphalen - RS, v. 21, n.2, p. 11-24, maio/ago. 2020. Recebido em: 13/03/2020 Aceito em: 25/05/2020 
No Brasil, constata-se que uma significativa parcela de estudantes que frequentam 0 ensino público noturno (CAPUCHO,2002), e não diferente aos alunos do EJA, são pessoas que mediante fatores sociais, econômicos, políticos e naturais, em um determinado momento da vida, tiveram que optar entre a escola e a atividade profissional, visto que era necessário garantir a sua existência e, posteriormente, a da sua família. Contudo, "é fundamental identificar os seus saberes, saberes estes que detém pela vivência e não pelo conhecimento teórico dos livros" (SANTOS, 2016, p. 208).

Os conhecimentos adquiridos na vida em sociedade e suas experiências individuais e coletivas são importantes para compreender características e perfis dos educandos, logo, deverão ser utilizados ou reaproveitados no ambiente escolar para que se estabeleçam conexões com 0 mundo das ciências e com o objetivo de provocar novos debates, suscitar reflexões e gerar autonomia mediante possíveis desafios encontrados na sociedade e no mundo contemporâneo.

Entretanto, a oferta da EJA no Brasil é marcada pelos avanços e retrocessos (CAPUCHO, 2012). Ainda que o país busque a adoção de modelos de resultados de sucesso de curto e médio prazo alcançados pelos países desenvolvidos, o modelo brasileiro mostra-se ineficaz e inoperante perante os problemas apresentados. Os esforços desenvolvidos pelo governo federal, ora pelos recursos próprios oriundos dos impostos e tributos canalizados para a educação, ora pela parceria público-privado, tem-se mostrado não tão significativos quanto o esperado.

Os programas federais de educação para essa modalidade de ensino direcionam teoria/ execução de suas propostas para os estados e os municípios, que a priori são repassados e implantados nas unidades escolares tendo máxima responsabilidade atribuídas aos diretores, coordenadores e professores, visando alcançar metas/resultados semestrais, bimestrais e anuais que atendam as necessidades do governo federal e do Ministério da Educação (MEC).

A proposta de uma educação libertadora, emancipatória e autônoma, esbarra em diferentes elementos que convergem para resultados insatisfatórios da educação nacional. Materiais obsoletos ou ultrapassados, planejamentos inadequados, professores improvisados ou sem qualificação adequada e o desconhecimento da história dos educandos são alguns dos fatores que contribuem para a não efetivação do ensino de qualidade. Mediante os fatores elencados, notamos que o ensino público noturno direcionado para os jovens e os adultos não supre as reais necessidades e os anseios desses educandos. Sendo assim, a escola ainda produz e reproduz em diversos casos o modelo de ensino tradicional, da memorização, da repetição e da exclusão que não corresponde às expectativas dos alunos e às transformações ocorridas na sociedade do século XXI. Neste sentido: 
Os sistemas de ensino sofrem uma demanda para se adaptarem às mudanças econômicas e sociais, tendo em vista que a nova matriz cognitiva deverá acompanhar os investimentos concentrados atualmente nos segmentos de telecomunicação, informática, financeiro, diversões e turismo. Esses setores exigem não apenas vultosos investimentos, mas profissionais altamente qualificados e polivalentes, ou seja, capazes de desenvolver habilidades básicas e complementares para alimentar a produção tecnológica, além de dominar línguas estrangeiras (MARTINS, 2002, p. 101).

Mediante diversas dificuldades, somados aos fatores intraescolar e extraescolar, é comum que muitas vezes a escola não seja vista pelos alunos como lugar de recomeço, da oportunidade e da inclusão social. A desmotivação e a vivência de uma educação não inclusiva são traduzidas na evasão e na repetência estudantil para os alunos da EJA. A evasão muitas vezes está relacionada à falta de significado que a escola tem na vida desses estudantes. A repetência tem relação direta com a falta de motivação de ir e permanecer na escola.

Essas e outras situações refletem uma educação que não é capaz de mediar conhecimentos significativos aos estudantes para resgatar a sua cidadania e dignidade perante aos novos desafios de um mundo marcado pela velocidade constante da informação e comunicação, tendo as tecnologias como agente mediador.

\section{Educação de Jovens e Adultos: um fortalecimento para a cidadania}

É válido reconhecer que o século XXI trouxe diversos avanços econômicos, científicos, sociais e tecnológicos, outrora não alcançados pela sociedade. Como um percurso historiográfico, a sociedade contemporânea desfruta das descobertas dos novos avanços das ciências humanas, através dos esforços de homens e mulheres que se dedicam visando ao bem comum. No campo da educação, diversos movimentos de cunho civil e político têm contribuído acerca de novos debates para a construção de uma educação pública, subjetiva, autônoma e gratuita, baseandose na dignidade da pessoa humana. Na visão de Capucho (2012, p. 114):

Uma sociedade marcada pelas contradições socioeconômicas e socioambientais, como a brasileira, decorrentes da exploração do(a) trabalhador(a) e do meio ambiente, expõe injustiças de diversas ordens as quais colocam em vulnerabilidade grande parte da população desafiando o Estado quando compromissado a promoção da justiça social, a proteger os seus direitos.

A violação de direitos e garantias individuais e coletivos no Brasil encontra resistência incessante de grupos majoritários e excluídos da sociedade que buscam a participação e a inclusão sobre novos debates e perspectivas sobre a vida em sociedade (BATTESTIN; WEYH, 
2019). A luta pela democracia efetiva-se formal e universalmente quando há sistematização e reconhecimento pelos diferentes grupos da sociedade como negros, índios, brancos, homens, mulheres, idosos, entre outros, que reconhecem individual e/ou coletivamente seus direitos e quando estes são assegurados e respeitados no exercício da cidadania. O exercício da cidadania é também validado e garantido no oferecimento de uma escola pública que garanta o acesso e a permanência dos indivíduos, buscando independência, qualidade e autonomia perante a sociedade.

Assim, entendemos que o uso das tecnologias no ambiente escolar, como elemento de aprendizagem e cidadania, deve ser compreendido como uma proposta de inclusão e emancipação, diante das exigências do mundo moderno. No tocante ao exercício da práxis pedagógica, novas possibilidades surgem motivadas por demandas socioeconômicas e no oferecimento e manutenção do ensino de qualidade. Segundo Brito e Purificação (2008, p. 23):

\footnotetext{
Vivemos em uma sociedade movida pelas tecnologias no cotidiano do homem rural ou urbano, ocorrem em situações em que as tecnologias se faz presente e necessária. Diante dessa afirmativa, assume-se, então, educação e tecnologia como ferramentas que podem proporcionar ao sujeito a construção do conhecimento, operacionalizandoos e desenvolvendo-os.
}

Dessa forma, novas ideias, posicionamentos e correntes filosóficas vislumbram novas possibilidades diante das exigências de um mundo em constantes transformações. Nessa proposta de educação contemporânea, os equipamentos tradicionais de suporte pedagógico como giz, quadro e livros, entre outros, dialogam parcialmente como novos elementos que propiciam ampliar o repertório da escola e do professor na busca pelo real significado e desejo da educação transformadora. Desse modo, busca-se maximizar o conhecimento através de diversos meios que possibilitem o melhor aprendizado. Na visão de Carvalho (2006, p. 260):

\begin{abstract}
A aplicação de ferramentas que proporcionam facilidades no entendimento do aluno tem sido buscada e aderida com mais frequência no ambiente escolar. A inovação, a criatividade, e a dinamização são encontradas na internet e há diversos recursos que trabalham com todos os sentidos das crianças e jovens. Diante dessa realidade, um dos desafios da escola e dos professores é de se adaptar para fazer melhor aproveitamento das TIC, inovando a maneira de comunicação e transmissão de conteúdos programáticos, possibilitando maior interação e integração entre professores e alunos estimulando 0 aprendizado.
\end{abstract}

Atualmente, as escolas e os professores são desafiados perante as novas mudanças tecnológicas introduzidas no ambiente escolar. Ainda que a rede mundial de computadores internet - seja um elemento relativamente novo sob a perspectiva de uso de recurso pedagógico em relação ao real sentido da internet para uso social e educacional (CARVALHO, 2006). 
A internet tem contribuído de forma significativa para novas formas de pesquisas, interações entre estudantes visando ao ensino e à aprendizagem. Nos últimos anos, diversos elementos tecnológicos fixos e móveis como computadores, tabletes, smartfhones, entre outros, deram e vêm dando aos professores e alunos uma maior autonomia e independência para a construção da aprendizagem.

O ambiente escolar, mais especificamente a sala de aula, necessita experienciar as tecnologias, de modo que possa contribuir com as dinâmicas estabelecidas pela sociedade, apresentando aos estudantes da EJA condições de inclusão no contexto social. Nessa proposta de educação, as tecnologias de aprendizagens têm ganhado novas funcionalidades pedagógicas para atender as necessidades da educação. O professor tornou-se um profissional que cada vez mais necessitará de constante atualização em diversas dimensões, sendo a tecnológica necessária e urgente, uma vez que "a prática pedagógica pode nos permitir chegar aonde almejamos. É preciso coerência entre a reflexão e a ação para construir o inédito viável, para construir novos cenários" (BATTESTIN; WEYH, 2019, p. 332).

Ainda que o uso de diferentes tecnologias da informação e da comunicação como recurso pedagógico, nos ambientes das escolas públicas, não seja utilizado com percentuais significativos, segundo a LDB/1996, é garantida ao profissional do magistério a educação continuada visando contribuir para a atualização do conhecimento, a profissionalização das atividades e a valorização desse profissional.

A garantia e o exercício de uma educação continuada para a oferta de ensino de qualidade para os alunos do EJA tem o sentido de corrigir distorções, garantir a inclusão e incentivar a emancipação para um grupo que historicamente foi negado e excluído de participação na vida social, econômica e cultural do país. Segundo Barros (2019, p. 183), "os sujeitos de EJA tem sua origem social nas camadas mais pobres e nelas permanecem, não recebendo nenhuma assistência e atendimento as suas mínimas condições de sobrevivência humana. Não têm garantidos os seus direitos sociais básicos, como saúde, educação, trabalho e alimentação".

A introdução das TIC no ambiente educacional da modalidade EJA tem um propósito inovador e motivacional, tendo em vista a grande evasão escolar e a desmotivação em permanecer e avançar nos estudos regulares oferecidos nas escolas públicas do país. $\mathrm{O}$ uso das tecnologias na educação corrobora com possibilidades de novas descobertas de ensino com eficiência e eficácia para a inclusão, emancipação e autonomia dos estudantes, buscando atingir a oferta de qualidade. 
Diferentes equipamentos eletrônicos como tabletes, celulares, smartphones, lousa eletrônica etc. podem mediar a construção de aulas diferentes e produtivas, favorecendo aproximação cada vez mais de alunos e professores visando ao conhecimento. Assim, as tecnologias têm o papel relevante e fundamental para novas perspectivas de mudanças adaptando as escolas às novas exigências da sociedade contemporânea.

\section{Considerações finais}

As escolas ainda são, na contemporaneidade, locais da divulgação e reprodução dos conhecimentos das ciências com vistas às benesses para a sociedade. É nelas que grande parte dos seres humanos recebe, durante um significativo período de suas vidas, conhecimentos formais indispensáveis para convívio em sociedade. 0 fazer pedagógico convida a refletir sobre novas atitudes de ação-reflexão-ação diante das necessidades de mudanças sobre novos contextos e práticas pedagógicas na atualidade.

Nos dias de hoje, desde cedo crianças, jovens, adultos e idosos são inseridos/convidados a conviver com um modelo de educação em que seus ensinamentos são mediados pelas diferentes TIC. As diferentes formas e usabilidade das tecnologias para educação pública e, em particular aquelas direcionadas para o público da Educação de Jovens e Adultos, trazem novas perspectivas de apropriação do conhecimento, conduzindo a uma maior aproximação entre estudantes e professores, diminuindo as distâncias presentes em um passado não tão distante.

O uso correto e planejado de tabletes, celulares, computadores, internet, entre outros recursos tecnológicos amplia as possibilidades dos professores na estruturação das atividades escolares e extraescolares objetivando a autonomia e corrigindo distorções. A organização do tempo e a racionalidade do trabalho a partir do uso das tecnologias permitirá, na busca pela qualidade, identificar as dificuldades individuais e coletivas, criar gráficos de desempenhos e reestruturar o planejamento de acordo com as necessidades da turma. Neste sentido, a EJA necessita de aulas que identifiquem e proponham a inclusão, o acesso e o domínio das tecnologias aproximando os estudantes de suas reais necessidades, garantindo a mediação no contexto do ensino e da aprendizagem, bem como a permanência e a sequência nos estudos.

As diferentes formas de acesso à construção do conhecimento a partir da mediação das tecnologias conduzem alunos e professores para interações colaborativas diante dos desafios 
propostos. As múltiplas possibilidades de conhecimentos permitem que os discentes desenvolvam novas habilidades físicas e cognoscentes para adquirir conhecimentos.

No campo das possibilidades, a disciplina como matemática pode adotar os jogos educativos digitais como forma de contribuir para a compreensão da complexidade dos números, a disciplina de português pode apropriar-se das plataformas digitais para fomentar leitura e a escrita visando ao melhor desempenho para a compreensão de textos, a geografia pode permitir que, em tempo real, os estudantes possam visualizar um determinado lugar nas escalas local, regional ou global. Diante desse repertório, todas as disciplinas podem adaptar o seu conteúdo para melhor contribuir para o ensino e a aprendizagem, objetivando o aprender se divertindo e divertir-se aprendendo.

O aparelhamento das escolas através dos laboratórios de informática e a disponibilidade de acesso à rede mundial de computadores (internet) viabilizam em tempo real conteúdos para todas as idades, os sites e plataformas digitais direcionam os estudantes para aprender novos ensinamentos de forma autônoma e interativa, mediada pelos professores que cada vez são conduzidos a atualizar o conhecimento, contudo atuando como mediadores do conhecimento.

Livros digitais são cada vez mais utilizados para direcionar os estudantes como uma ampla fonte de pesquisa que não se esgota em si, mas oportunizam o acesso com dinamicidade do conhecimento. Ainda que a composição da sala do EJA seja marcada pela heterogeneidade de pessoas e que a aprendizagem seja absorvida pelas diferentes habilidades e atitudes dos docentes, a capacidade de articulação de mídias do conhecimento é fundamental para que 0 professor utilize o mais eficiente meio de atingir a mediação e a participação dos envolvidos.

A educação digital e os seus recursos tecnológicos desafiam as escolas, os alunos e os professores diante de novas habilidades e aptidões do conhecimento. As práticas pedagógicas são e serão marcadas pela capacidade de mediar novos ensinamentos mais dinâmicos e interativos, as avaliações terão novos significados diante das exigências do convívio em sociedade e associadas às dinâmicas do mundo do trabalho, os professores serão motivados pela necessidade de atualização e reformulação do planejamento e os alunos cada vez mais adquirirão novas posturas e habilidades diante dos desafios provocados através do conhecimento.

\section{REFERÊNCIAS}

BARROS, Abdizia Maria Alves. A Política de Formação de Professores da EJA: repercussão na prática pedagógica. Maceió: Edufal, 2019. 
BATTESTIN, Cláudia; WEYH, Cênio Back. A perspectiva político-pedagógica na educação popular de Paulo Freire e a relevância de seu pensamento. Educação: Teoria e Prática, Rio Claro, SP, v. 29, n.61/ p. 321-335/ Maio-Ago. 2019.

BRASIL. Constituição Federal de 1988. Brasília, 1988.

BRASIL. Lei de Diretrizes e Bases da educação Nacional (1996). Biblioteca Digital da Câmara dos deputados. Lei nº 9.394 de 20 de dezembro de 1996.

BRITO, Glaucia S.; PURIFICAÇÃO, Ivonélia. Educação e Novas Tecnologias: um (re) Pensar. Curitiba: Ibpex, 2008.

CAPUCHO, Vera. Educação de Jovens e Adultos: Prática Pedagógica e Fortalecimento da Cidadania. São Paulo - SP: Cortez, 2012.

CARVALHO, Rosita Edler. Escola Inclusiva: com os pingos nos "is". Porto Alegre, $4^{\mathrm{a}}$ ed., Mediação, 2006.

CUNHA, Maria Isabel da. 0 bom professor e a sua prática. Campinas - SP: Papirus, 2006.

FREIRE, Paulo. Ação Cultural para Liberdade e Outros Escritos. São Paulo - SP: Editora Paz e Terra S/A, 2007.

LUNA, Sérgio V. de. O falso conflito entre tendências metodológicas. In: FAZENDA, Ivani (Org.). Metodologia da pesquisa educacional. São Paulo: Cortez, 2000.

MAGALHÃES, Fernando. Tempos Pós-modernos. São Paulo: Cortez Editora, 2004.

MARTINS, Ângela Maria. Autonomia da Escola: a (ex)tensão do tema nas políticas públicas. São Paulo: Cortez Editora, 2002.

MORAN, José Manuel; MASETTO, Marcos T; BEHRENS, Marilda Aparecida. Novas Tecnologias e Mediação Pedagógica. Campinas - SP, Papirus, $21^{a}$ Edição revista e atualizada, 2013.

OLIVEIRA, Maria Auxiliadora Monteiro. Gestão Educacional: novos olhares, novas abordagens. Petrópolis: Vozes, 2005.

SANTOS, Milton. A Urbanização Brasileira. São Paulo - SP: Edusp, 1988.

SANTOS, Milton. Metamorfoses do Espaço Habitado. São Paulo - SP; Edusp, 2016. 